\title{
A Case of Paraneoplastic Demyelinating Motor Polyneuropathy
}

\author{
Sohrab Mostoufizadeh ${ }^{a}$ Maryam Souri $^{b}$ \\ Jérôme de Seze \\ a'Département de Neurologie, Hôpitaux Universitaires, Strasbourg, France; \\ ${ }^{\mathrm{b}}$ Medical Education Development Center, University of Medical Sciences, \\ Tehran, Iran
}

\section{Key Words}

Motor neuropathy - Conduction block - Paraneoplastic neuropathy - Cancer .

Onconeural antibodies . Anti-ganglioside antibodies

\section{Abstract}

Peripheral neuropathy is commonly accompanied by cancer but demyelinating ones are not commonly reported. We report the clinical, neurophysiological, and biological characteristics of an 82-year-old patient who presented with a demyelinating motor neuropathy and high titre of anti-ganglioside antibodies associated with oesophageal cancer. The neurological course worsened rapidly despite immunotherapy, leading to a bedridden status. We propose to suspect a paraneoplastic origin in older patients or when the clinical course progresses rapidly within a few weeks or months.

\section{Introduction}

Paraneoplastic neurological syndromes are a heterogeneous group of neurological disorders occurring in less than $1 \%$ of patients with malignancy [1]. Peripheral neuropathy is commonly accompanied by cancer but paraneoplastic neuropathies which show a pure demyelinating pattern on electrophysiological studies are not commonly reported [2].

\section{Case Report}

An 82-year-old patient was referred for a subacute rapidly progressive tetraparesis. He had presented with anorexia, asthenia and repeated falls since one month and was admitted 2 weeks ago for these complaints in the setting of a biologic inflammatory syndrome. He had no significant past 
medical history, neither alcohol abuse nor toxic substance exposure nor a significant family history. First neurological examination at admission showed a distal paraparesis and lower limb reflex abolition. Motor force was otherwise normal. At this time, clinical examination revealed motor deficit extension in the proximal areas of the 4 limbs with complete reflex abolition. Sensitive cerebellar and cranial nerve examination was normal.

Electromyography revealed a pure motor demyelinating polyneuropathy of the four limbs with several conduction blocks between 55 and 90\% in the upper limbs (fig. 1). No motor response was detected in the lower limbs and neither tibial F-wave nor H-reflex were recordable (table 1). On needle electromyography, we observed denervation potentials in the distal muscles of the four limbs. Complete blood count revealed a leucocytosis at $12,000 / \mathrm{mm}^{3}$. Biological tests showed a raised C-reactive protein level at $75 \mathrm{mg} / \mathrm{l}$, with normal renal, hepatic and thyroid function tests. HIV serology was negative. Cerebrospinal fluid analysis showed 75 leucocytes $/ \mathrm{mm}^{3}$ and a hyperproteinorachia at $1.01 \mathrm{~g} / \mathrm{l}$ without any malignant cells. Cerebrospinal fluid immunoglobulin dosage showed an elevated IgG level of $308 \mathrm{~g} / \mathrm{l}$ (normal: 10-34). We did not find any Herpesviridae family or Borrelia burgdorferi infections. Immunological tests showed anti-GD1a (IgM at 1/2,000 and IgG >1/10,000), anti-GD1b $\operatorname{IgM}$ at 1/5,000, anti-GM1 IgM at 1/5,000 and onconeural (anti-gray matter and anti-cerebellar) antibodies in the serum. Serum protein electrophoresis was normal.

As an immune-mediated neuropathy was suspected, the patient was treated by one course of IVIg $(2 \mathrm{~g} / \mathrm{kg})$ and corticosteroid pulse without any response to therapy. His general status worsened and the patient became bedridden soon thereafter. The presence of onconeural antibodies and general status worsening led to a large workup. An oesophageal mass was detected by thoraco-abdominopelvic computed tomography. A transendoscopical biopsy confirmed the diagnosis of epidermoid oesophageal carcinoma. At this time, the patient did not have any metastases or any cancer-related complaints. Following a multidisciplinary approach, the patient was treated merely by palliative radiotherapy and died 4 months later.

\section{Discussion}

\section{Differential Diagnosis}

The progressive pure motor symptoms in the setting of a demyelinating neuropathy associated with conduction blocks in electromyography and presence of a high anti-GM1 antibody titre favour the diagnosis of multiple motor neuropathy (MMN). However, late-age onset and a 50\% decrease in distal amplitude of the sensory ulnar nerve are not typical of this diagnosis $[3,4]$.

Initial clinical presentation may be concordant with a motor variant of Guillain-Barré syndrome (GBS). Moreover, in a large study of 147 patients with GBS, high titres of anti-GM1 antibodies were significantly more common in motor GBS patients. However, electrophysiological data of these patients revealed little or no evidence for demyelination [5]. High titres of anti-GD1a antibodies have been found in patients with GBS but were also found in $18 \%$ of patients with MMN and $5 \%$ of those with chronic inflammatory demyelinating polyneuropathy (CIDP) [6].

A chronic (>2 months) course and electrophysiologic findings can raise the possibility of CIDP and there are patients eventually diagnosed with CIDP who have an acute onset resembling GBS; however, acute-onset CIDP should be suspected in patients with prominent sensory symptoms and signs at presentation [7].

Conduction blocks are the electrophysiological hallmarks of Lewis and Sumner syndrome as well but the major distinguishing features between Lewis and Sumner syndrome and motor neuropathy with block are the clinical and electrophysiological 
sensory involvement and lack of anti-GM1 antibodies in Lewis and Sumner syndrome [8].

Another paraneoplastic neuropathy which is a classical one is a sensory ganglionopathy characterized by non-length-dependent abnormalities of sensory nerve action potentials. However, clinical and electrophysiological patterns of our patient did not correspond with this entity [9].

We could not determine the subtype diagnosis of this demyelinating motor neuropathy; based on initial clinical presentation, the diagnosis of GBS was likely but the electrophysiological findings are in favour of CIDP or MMN with some atypical features.

\section{Paraneoplastic Origin}

There are different mechanisms by which cancer affects the peripheral nervous system (PNS). These mechanisms can include compression or infiltration by the tumour, deleterious effects of treatments, metabolic and nutritional factors and infections. Paraneoplastic PNS involvements, however, are not explained by any of these mechanisms [1]. It has been proposed to classify paraneoplastic PNS disorders as definite or possible according to the presence or absence of the following items: classical paraneoplastic PNS disorder, onconeural antibodies and development of cancer $[1,10]$.

Our patient presented with a non-classical neurological syndrome but the presence of onconeural antibodies and cancer occurrence within less than 5 years following neurological symptoms confirm the diagnosis of definite paraneoplastic polyneuropathy.

Cases of demyelinating neuropathies in association with solid tumours are rare. GBS was reported accompanying endometrial, cholecystic, bronchial, renal, hepatic and gastric carcinoma [11-16]. However, in many of these cases, it is difficult to determine whether GBS should all the time be considered paraneoplastic because the frequency of both cancer and GBS makes a coincidental association possible. There are also reports of CIPD associated with solid carcinoma including melanoma, breast, gastric, pancreas, liver and colon carcinoma [17-23]. As for GBS, paraneoplastic syndromes are highly suggested in these cases but the frequent lack of antineuron antibodies makes the link between the two diseases uncertain. To our knowledge, there is no case report of MMN associated with cancer. However, in the last decade, there were some reports of MMN associated with haematological malignancies [24, 25]. Viala et al. [26] proposed that in the setting of demyelinating neuropathies, either a severe or rapid course, a poor response to therapy with an early axonal loss or the presence of systemic abnormalities should lead to suspect an associated lymphoma.

It would be interesting to reconsider the course of neuropathy in our patient. The neuropathy had a rapid course with early axonal loss witnessed by inexcitability of both peroneal and tibial nerves and a poor response to treatment. Unfortunately, in our case there was no indication for tumour resection, but the findings in the literature are generally consistent with clinical improvement of paraneoplastic demyelinating neuropathy following a solid tumour resection $[21,27]$. 


\section{Conclusion}

In conclusion, we suggest looking for a paraneoplastic origin in the setting of demyelinating neuropathy in older patients, or when the clinical course is progressing rapidly within a few weeks or months.

\section{Disclosure Statement}

The authors have no conflicts of interest to declare.

Table 1. Results of nerve conduction study

\begin{tabular}{|c|c|c|c|c|}
\hline Nerve & Parameter & Normal values & Left side & Right side \\
\hline \multirow[t]{4}{*}{ Tibial motor } & Distal amplitude, mV & $>5.9$ & NR & NR \\
\hline & Proximal amplitude, mV & & NR & NR \\
\hline & Latency, ms & $<6.3$ & NR & NR \\
\hline & Conduction velocity, m/s & $>44$ & NR & NR \\
\hline \multirow[t]{4}{*}{ Peroneal } & Distal amplitude, mV & $>2.3$ & NR & NR \\
\hline & Proximal amplitude, $\mathrm{mV}$ & & NR & NR \\
\hline & Latency, ms & $<5.9$ & NR & NR \\
\hline & Conduction velocity, m/s & $>43$ & NR & NR \\
\hline \multirow[t]{6}{*}{ Ulnar motor } & Distal amplitude $\mathrm{W}, \mathrm{mV}$ & $>4.5$ & 1.3 & 4.0 \\
\hline & Proximal amplitude BE, mV & & $0.192(86 \%)^{*}$ & $1.0(75 \%)^{*}$ \\
\hline & Proximal amplitude AE, mV & & $0.083(57 \%)^{*}$ & 1.0 \\
\hline & Proximal amplitude Erb, $\mathrm{mV}$ & & 0.065 & $0.048(95 \%)^{*}$ \\
\hline & Latency, ms & $<3.4$ & 2.1 & 2.8 \\
\hline & Conduction velocity $\mathrm{W}-\mathrm{BE}, \mathrm{m} / \mathrm{s}$ & $>50$ & 59.1 & 46.9 \\
\hline \multirow[t]{5}{*}{ Median motor } & Distal amplitude, $\mathrm{mV}$ & $>5.6$ & 4.3 & 3.6 \\
\hline & Proximal amplitude E, mV & & $2.0(55 \%) *$ & $0.46(87 \%)^{*}$ \\
\hline & Proximal amplitude Erb, mV & & $0.18(91 \%)^{*}$ & $0.12(78 \%) *$ \\
\hline & Latency, ms & $<4.0$ & 3.1 & 3.6 \\
\hline & Conduction velocity $\mathrm{W}-\mathrm{E}, \mathrm{m} / \mathrm{s}$ & $>49$ & 50 & 48 \\
\hline Tibial & F-Wave latency, m/s & $<55$ & NR & NR \\
\hline Ulnar/median & F-Wave latency, m/s & $<28$ & ND & ND \\
\hline \multirow[t]{3}{*}{ Sural } & Distal amplitude, $\mu \mathrm{V}$ & $>3.5$ & 8.1 & ND \\
\hline & Latency, ms & $<3.8$ & 1.7 & ND \\
\hline & Conduction velocity, m/s & $>45$ & 46.8 & ND \\
\hline \multirow[t]{3}{*}{ Ulnar sensory } & Distal amplitude, $\mu \mathrm{V}$ & $>6.0$ & ND & 3 \\
\hline & Latency, ms & $<3.2$ & ND & 2.8 \\
\hline & Conduction velocity $\mathrm{W}-\mathrm{BE}, \mathrm{m} / \mathrm{s}$ & $>47$ & ND & 44.6 \\
\hline Tibial & H-reflex latency, m/s & $<34$ & NR & NR \\
\hline
\end{tabular}

$\mathrm{AE}=$ Above elbow $; \mathrm{BE}=$ below elbow $; \mathrm{E}=$ elbow $; \mathrm{Erb}=\mathrm{Erb}$ point $; \mathrm{ND}=$ note done $\mathrm{NR}=$ not recordable $\mathrm{W}=$ wrist. Abnormal values are in bold. ${ }^{*}$ Conduction block. Decline in negative peak amplitude of the motor response is indicated as percentage. 


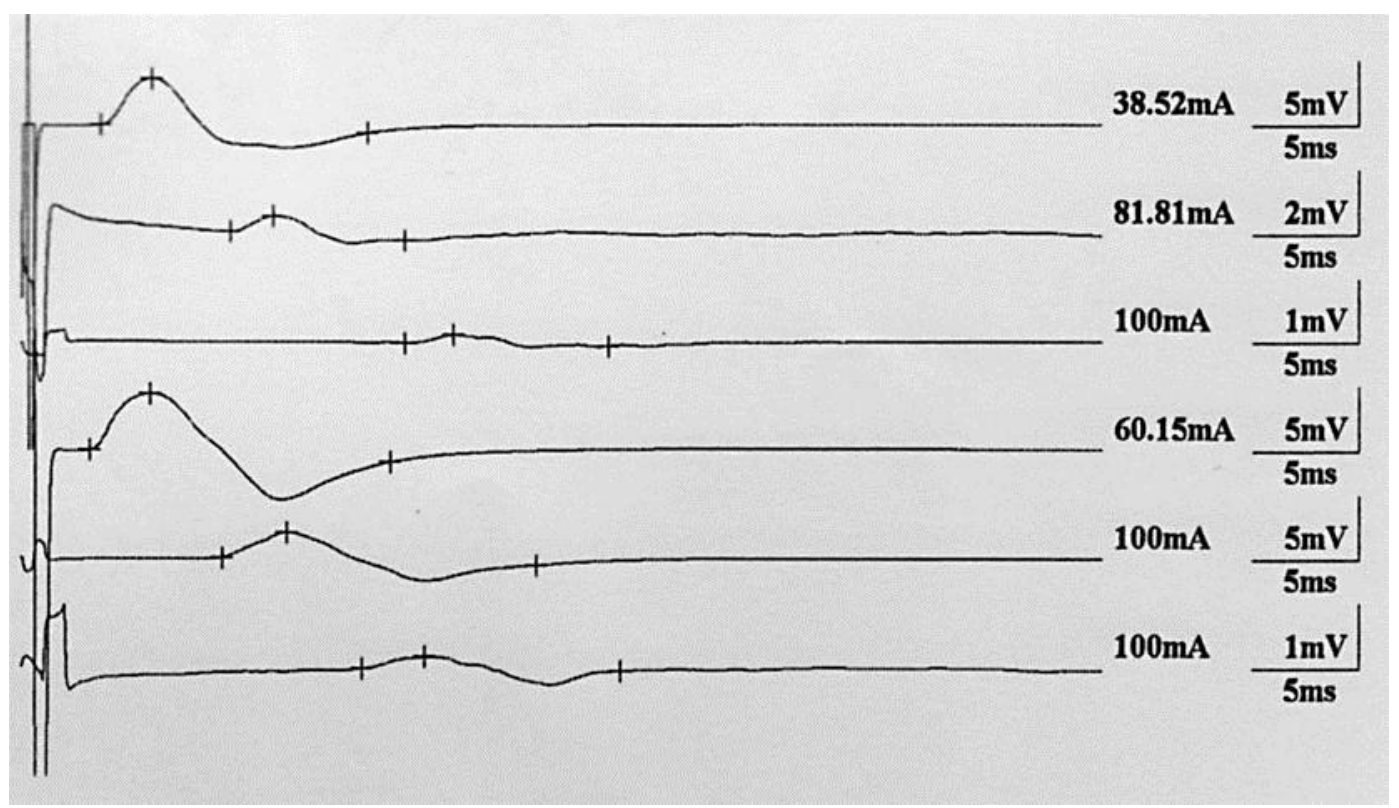

Fig. 1. Conduction block in median nerves. Right limb in the upper half and left limb in the lower one. Nerve stimulation at the wrist, elbow and Erb point in an up-to-down order. The decline in negative peak amplitude was between 55 and $90 \%$ in comparison with distal stimulation.

\section{References}

-1 Antoine JC, Camdessanché JP: Peripheral nervous system involvement in patients with cancer. Lancet Neurol 2007;6:75-86.

2 Toothaker TB, Rubin M: Paraneoplastic neurological syndromes: a review. Neurologist 2009;15:21-23.

- 3 Van Asseldonk JTH, Franssen H, Van der Berg-Vos R, Wokke JHJ, Van der Berg L: Multifocal motor neuropathy. Lancet Neurol 2005;4:309-319.

$\checkmark 4$ Joint Task Force of the EFNS and the PNS: European Federation of Neurological Societies/Peripheral Nerve Society guideline on management of multifocal motor neuropathy. Report of a Joint Task Force of the European Federation of Neurological Societies and the Peripheral Nerve Society - first revision. J Peripher Nerv Syst 2010;15:295-301.

-5 Visser LH, Van der Meché FGA, Van Doorn PA, Meulstee J, Jacobs C, Oomes PG, Kleyweg RP, Meulstee J: Guillain-Barré syndrome without sensory loss (acute motor neuropathy). A subgroup with specific clinical, electrodiagnostic and laboratory features. Dutch Guillain-Barré Study Group. Brain 1995;118:841-847.

-6 Carpo M, Nobile-Orazio E, Meucci N, Gamba M, Barbieri S, Allaria S, Scarlato G: Anti-GD1a ganglioside antibodies in peripheral motor syndromes. Ann Neurol 1996;39:539-543.

-7 Van den Bergh PY, Hadden RD, Bouche P, Cornblath DR, Hahn A, Illa I, Koski CL, Léger JM, Nobile-Orazio E, Pollard J, Sommer C, van Doorn PA, van Schaik IN; European Federation of Neurological Societies; Peripheral Nerve Society: European Federation of Neurological Socities/Peripheral Nerve Society Guideline on management of cheronic inflammatory demyelinating polyradiculoneuropathy: report of a joint task force of the European Federation of Neurological Societies and the Peripheral Nerve Society first revision. Eur J Neurol 2010;17:356-363.

8 Verschueren A, Azulay JP, Attarian S, Boucraut J, Pelissier JF, Pouget J: Lewis-Sumner syndrome and multifocal motor neuropathy. Muscle Nerve 2005;31:88-94.

9 Kuntzer T, Antoine JC, Steck AJ: Clinical features and pathophysiological basis of sensory neuronopathies (ganglionopathies). Muscle Nerve 2004;30:255-268. 
10 Graus F, Delattre JY, Antoine JC, et al: Recommended diagnostic criteria for paraneoplastic neurological syndromes. J Neurol Neurosurg Psychiatry 2004;75:1135-1140.

11 Tho LM, O'Leary CP, Horrocks I, Al-Ani A, Reed NS: Guillain Barré syndrome occurring after adjuvant chemo-radiotherapy for endometrial cancer. Gynecol Oncol 2006;100:615-617.

-12 Phan TG, Hersch M, Zagami AS: Guillain Barré syndrome and adenocarcinoma of the gall bladder: a paraneoplastic phenomenon? Muscle Nerve1999;22:141-142.

13 Mineo TC, Biancari F, Casciani CU: Polyradiculoneuritis as an initial manifestation of bronchial carcinoma. J Thorac Cardiovasc Surg 1995;109:1254.

14 Swan CHJ, Wharton BA: Polyneuritis and renal carcinoma. Lancet 1963;ii:383-384.

15 Calvey HD, Melia WM, Williams R: Polyneuropathy: an un-reported non-metastatic complication of primary hepatocellular carcinoma. Clin Oncol 1983;9:199-202.

16 Tola-Arribas MA, Cañibano-González MA: Guillain-Barré syndrome associated with gastric adenocarcinoma. Paraneoplastic origin or coincidence? Rev Neurol 2001;33:797-798.

17 Antoine JC, Mosnier JF, Absi L, Convers P, Honnorat J, Michel D: Carcinoma associated paraneoplastic peripheral neuropathies in patients with and without anti-onconeural antibodies. J Neurol Neurosurg Psychiatry 1999;67:7-14.

-18 Antoine JC, Mosnier JF, Lapras J, Convers P, Absi L, Laurent B, Michel D: Chronic inflammatory demyelinating polyneuropathy associated with carcinoma. J Neurol Neurosurg Psychiatry 1996;60:188190.

19 Arguedas RM, Mcguire BM: Hepatocellular carcinoma presenting with chronic inflammatory demyelinating polyradiculoneuropathy. Dig Dis Sci 2000;45:2369-2373.

20 Abe K, Sugai F: Chronic inflammatory demyelinating polyneuropathy accompanied by carcinoma. J Neurol Neurosurg Psychiatry 1998;65:403-404.

21 Weiss MD, Luciano CA, Semino-Mora C, Dalakas MC, Quarles RH: Molecular mimicry in chronic inflammatory demyelinating polyneuropathy and melanoma. Neurology 1998;51:1738-1741.

22 Chawla JPS, Fisher AM: Gastric carcinoma presenting with chronic inflammatory demyelinating polyneuropathy. The Internet Journal of Neurology 2007;7.

-23 Rajabally YA, Qaddoura B, Abbott RJ: Steroid-responsive paraneoplastic demyelinating neuropathy and myelopathy associated with breast carcinoma. J Clin Neuromuscul Dis 2008;10:65-69.

-24 Stern BV, Baehring JM, Kleopa KA, Hochberg FH: Multifocal motor neuropathy with conduction block associated with metastatic lymphoma of the nervous system. J Neurooncol 2006;78:81-84.

$\checkmark 25$ Slee M, Selvan A, Donaghy M: Multifocal motor neuropathy: the diagnostic spectrum and response to treatment. Neurology 2007;69:1680-1687.

-26 Viala K, Béhin A, Maisonobe T, Léger JM, Stojkovic T, Davi F, Leblond V, Bouche P: Neuropathy in lymphoma: a relationship between the pattern of neuropathy, type of lymphoma and prognosis. J Neurol Neurosurg Psychiatry 2008;79:778-782.

-27 Lagrange E, Veran 0, Besson G: Pure motor relapsing Guillain Barré syndrome associated with anti-GM1 antibodies revealing urinary bladder cancer. Eur J Neurol 2007;14:e7. 